\title{
GENE-ENVIRONMENT INTERACTIONS BETWEEN STRESS AND 5-HTTLPR IN DEPRESSION: A META-ANALYTIC UPDATE
}

Dries Bleys*, KU Leuven, Faculty of Psychology and Educational Sciences, Tiensestraat 102, 3000 Leuven, Belgium

Patrick Luyten, KU Leuven, Faculty of Psychology and Educational Sciences, Tiensestraat 102, 3000 Leuven, Belgium, and University College London, Faculty of Brain Sciences, 1-19 Torrington Place, London WC1E7HB, United Kingdom

Bart Soenens, Ghent University, Department of Developmental, Personality and Social Psychology, H. Dunantlaan 2, 9000 Ghent, Belgium

Stephan Claes, KU Leuven, Research Group Psychiatry, Kapucijnenvoer 33, 3000 Leuven, Belgium

* Corresponding author at KU Leuven, Department of Clinical Psychology, Tiensestraat 102 box 3720, 3000 Leuven, Belgium. Tel. +32 163730 72. E-mail address: dries.bleys@kuleuven.be 


\begin{abstract}
Background: Meta-analyses have yielded contradictory findings concerning the role of 5-HTTLPR in interaction with stress $(\mathrm{GxE})$ in depression. The current meta-analysis investigates if these contradictory findings are a result of differences between studies in methodological approaches towards the assessment of stress and depression.
\end{abstract}

Methods: After performing a systematic database search (February to December 2016), first, a metaanalysis was used to investigate the total effect size and publication bias. Second, stratified metaanalyses were used to investigate the potential moderating influence of different methodological approaches on heterogeneity of study findings. Third, a meta-regression was used to investigate the combined influence of the methodological approaches on the overall effect size.

Results: Results showed a small but significant effect of 5-HTTLPR in interaction with stress in the prediction of depression $(\mathrm{OR}[95 \% \mathrm{CI}]=1.18[1.09 ; 1.28], \mathrm{n}=48$ effect sizes from 51 studies, totaling 51,449 participants). There was no evidence of publication bias. Heterogeneity of effect sizes was a result of outliers and not due to different methodological approaches towards the assessment of stress and depression. Yet, there was some evidence that studies adopting a categorical and interview approach to the assessment of stress report higher GxE effects, but further replication of this finding is needed.

Limitations: A large amount of heterogeneity (i.e., 46\%) was not explained by the methodological factors included in the study and there was a low response rate of invited studies.

Conclusions: The current meta-analysis provides new evidence for the robustness of the interaction between stress and 5-HTTLPR in depression. 


\section{INTRODUCTION}

Current theories of depression emphasize the interplay between environmental and biological factors in explaining vulnerability for this disabling disorder (Heim and Binder, 2012; Lesch, 2004; Lohoff, 2010). Much of this work has focused on the role of the serotonin-transporter-linked polymorphic region (5-HTTLPR), following the seminal work of Caspi and colleagues (Caspi et al., 2003). These authors were the first to report that the impact of life stress on depression was moderated by a polymorphism of the 5-HTT gene. Specifically, associations between stressful life events and depression were more pronounced among individuals with one or two copies of the short allele of 5HTTLPR. However, meta-analyses of subsequent studies have yielded contradictory conclusions concerning the role of an interaction between stress and 5-HTTLPR (GxE) in depression (Karg et al., 2011; Risch et al., 2009).

Various methodological factors that might account for these diverging findings have remained unexamined to date. First, extant research differs with regard to whether it adopts a categorical or a dimensional approach to depression and stress. Yet, with the exception of melancholic depression (Ambrosini et al., 2002; Haslam and Beck, 1994), taxometric studies suggest that depression is dimensionally distributed (Ruscio and Ruscio, 2000; Slade and Andrews, 2005). Similarly, both human and animal studies suggest that the underlying biological mechanisms involved in depression are dimensionally distributed (Charney and Manji, 2004; Nestler et al., 2002). Yet, many studies on GxE have adopted a categorical approach to assessing depression, which may moreover have resulted in a considerable loss of statistical power (Fraley and Spieker, 2003; Hankin et al., 2005). With regard to stress, there is an ongoing debate concerning the impact of stress on the risk for depression (Kessler, 1997; Tennant, 2002). Whereas some studies suggest a categorical threshold model, with the risk for depression increasing only after a certain stress threshold has been reached, other studies suggest a continuous effects model, arguing that the risk for depression simply increases as the number of stressful life events increases (Appleyard et al., 2005; Mitchell et al., 2015). Yet, no study to date has 
addressed the potential influence of a categorical versus dimensional approach to the assessment of depression and stress on interactions between 5-HTTLPR and stress in the prediction of depression.

Second, it remains equally unclear whether the way depression is assessed (i.e., by self-report questionnaires or interviews) influences findings concerning GxE in depression. Although studies suggest moderate to high agreement between both types of assessment (Eaton et al., 2000; Stuart et al., 2014), interview-based measures of depression are often considered the "gold standard" because selfreport questionnaires may be particularly prone to reporting bias (Enns et al., 2000; Hunt et al., 2003; Joiner et al., 2005; Logan et al., 2008). Similarly, in the domain of stress research, interview-based measures of stress are typically considered to be superior to self-report measures, as these latter measures would conflate stressful events and depressed mood (Hammen, 2005; Uher and McGuffin, 2008, 2010). Studies in this area, however, have yielded conflicting findings, with some studies suggesting that both measurement approaches lead to similar conclusions (Duggal et al., 2000; Lewinsohn et al., 2003), while other studies suggest that findings of an association between 5HTTLPR and depression may be stronger using interview-based measures of stress (Karg et al., 2011; Uher and McGuffin, 2010). Clearly, a formal meta-analytic test of the role of type of assessment is needed.

A third possible reason for the diverging results of meta-analyses of GxE effects in the prediction of depression may be related to the timing of stress. Although stressful life events occurring during adulthood have been shown to be related to the onset of depression (Kendler et al., 1999; Tennant, 2002), the relationship between early stress and depression might be stronger because of early sensitization effects (Anda et al., 2006; Hammen et al., 2000; Lupien et al., 2009; McLaughlin et al., 2010). To date, however, it is unknown whether the interaction effect between stress and 5-HTLLPR in depression differs as a function of the timing of adversity. 


\section{The Present Study}

Given the rapid growth of research in this area, the first aim of this study is to provide an updated meta-analysis of the interaction effects of 5-HTTLPR and stress in the prediction of depression. This update is urgently needed as the largest meta-analysis of GxE effect sizes in depression included only 14 studies (Risch et al., 2009). Also, we address potential publication bias in studies in this area (Kaufman et al., 2010).

Second, using stratified meta-analyses, we investigated the influence of dimensional versus categorical assessment of depression and stress, self-report versus interview-based assessment of depression and stress, and the timing of stress (i.e., early life stress versus stress in adulthood) as potential moderators of the interaction between 5-HTTLPR and stress in the prediction of depression.

Finally, we investigate the relative contribution of these potential moderators and their interactions on the magnitude of effect sizes within a meta-regression framework (van Houwelingen et al., 2002).

\section{METHOD}

\section{Studies}

From February 2016 to December 2016 potential studies were identified through a systematic search in databases (PubMed, SpingerLink, ScienceDirect, and Wiley Online Library using (combinations of) the following search terms with Boolean operators: "depression”, "depressive symptoms", "gene-environment interactions", "interaction", "stress", “trauma”, "5-HTTLPR”. In addition, reference lists of relevant meta-analyses and studies were hand searched for additional studies. Inclusion criteria were (a) full-text paper published in English; (b) human participants; (c) a candidate gene approach with identification of 5-HTTLPR; (d) environmental factors that are stressful for the individual, with the exclusion of residency and physical illness or accidents (e.g., hip fracture); (e) a depression related outcome factor (depression diagnoses / symptoms), excluding measures of negative emotionality, bipolar disorder, broader symptom clusters such as internalizing symptoms or 
anxious depression, and antidepressant treatment response. This led to the inclusion of 106 studies. Authors of studies containing insufficient data to calculate an effect size (see below) were contacted and asked to provide either the study data or to directly provide the needed additional data. Up to three consecutive e-mails ( 1 per month) were sent to multiple authors of the same study in case of nonresponse. The final number of included studies was 51. See Fig. A.1 in Appendices for the PRISMA flow diagram.

\section{Data extraction}

We extracted the following information from each identified study: (a) in case of categorical depression outcome, the regression coefficient and standardized error of the interaction term from a logistic regression or (b) in case of a continuous depression outcome, the difference in explained variance $\left(R^{2}\right)$ after inserting the interaction term in a hierarchical regression analysis or the partial eta squared $\left(\eta^{2}\right)$ belonging to the interaction term in an analysis of variance. All models included both main and interaction effects of the environmental stress factor and 5-HTTLPR (coded as LL-allele versus SS+SL-alleles). Moreover, we requested that results were restricted to biallelic coded 5HTTLPR and were controlled for gender (Sjöberg et al., 2006), ethnicity (Scheid et al., 2011), and twin status, although this was not always applicable or possible. When a study was longitudinal, we requested data for each time point. See Table A.1 in Appendices for details of studies and statistical analysis per study.

\section{Statistical analysis}

All effect sizes were transformed to log Odds Ratios (ORs; Cohen, 1988; Cooper et al., 2009; Lipsey and Wilson, 2001) using the statistical software R (R Development Core Team, 2014) and the packages "compute.es" (Del Re, 2013). By transforming different types of effect sizes into readily interpretable Odds Ratios, this meta-analysis included all studies simultaneously and different types of studies (e.g., continuous versus dichotomous depression outcome) could be directly compared in terms 
of effect sizes ${ }^{1}$. The meta-analysis was performed using the R package "meta" (Schwarzer, 2016). We applied the inverse variance method for the meta-analysis. Heterogeneity tests were performed using $I^{2}$,(Higgins et al., 2003) describing the percentage of variation across studies that is due to the heterogeneity and is not spurious (with $I^{2}=25 \%=$ low, $I^{2}=50 \%=$ moderate, $I^{2}=75 \%=$ high heterogeneity), and a test of the significance of the heterogeneity based on the $Q$ statistic (Cochran, 1950). Sensitivity analyses were performed to investigate the effect of leaving a study out on the overall effect size. We only discuss results of the random effects models, although for transparency, results of the fixed effects model of the overall meta-analysis are also presented in the figure. For estimation of the between-study variance, the adjustment of the weights in the random-effects metaanalysis, and for the meta-regression, the $\mathrm{Tau}^{2}$ estimate was used (DerSimonian and Laird, 1986).

For the overall meta-analysis, all available effect sizes were averaged per study (averaging also between effect sizes of studies that included the same sample), resulting in 48 effect sizes from 51 studies. We also inspected publication bias using a funnel plot. For the stratified analyses, effect sizes from identical samples were allowed if they were not present in the same subgroup. For the randomeffects meta-regression, available effect sizes were selected from the previous stratified analyses, regression predictors were the potential moderators and a control variable was included identifying effect sizes from the same sample to control for their interdependence (continuously coded: unique samples coded ' 0 ', studies with same sample ' 1 ', next set of studies with same sample ' 2 ', etc.). Cochran (1954) $Q_{E}$-test for residual heterogeneity was performed after introducing the predictors.

\section{RESULTS}

\section{Overall meta-analysis}

There was a small, but significant, GxE effect of 5-HTTLPR $(\mathrm{OR}[95 \% \mathrm{CI}]=1.18[1.09 ; 1.28], \mathrm{n}=$ 51 studies yielding 48 effect sizes, totaling 51,449 participants; Figure 1). There was significant

\footnotetext{
${ }^{1}$ A forest plot using the Cohen's $d$ effect size for all studies with a dimensional (continuous) depression score is available in Fig. A. 2 in Appendices.
} 
moderate to high heterogeneity between studies $\left(I^{2}=52.4 \%, Q=98.64, p<.0001\right)$. A sensitivity analysis showed no effect on the significance of the overall OR if one of the studies was omitted (Table A.2 in Appendices), not even if we omitted the two studies with the largest positive effect size, the study of Brown et al. (2013) and the study of Mehta et al. (2012) (overall OR[95\% CI] $=1.13$ $[1.07 ; 1.19])$. However, the $I^{2}$ heterogeneity index decreased to $21.0 \%$ and became non-significant $(p=$ $.106)$ if the study of Mehta et al. (2012) was omitted (OR[95\% CI $]=1.14[1.07 ; 1.20]$; Table A.2 in Appendices). There was no evidence for publication bias (Figure 2).

\section{Stratified meta-analyses}

None of the examined moderators had a significant influence on the heterogeneity of effect sizes of the GxE effect in separate stratified meta-analyses $\left(Q_{\text {between }}=1.13, p=.289\right.$, for categorical versus dimensional assessment of depression; $Q_{\text {between }}=1.86, p=.173$, for interview-based versus self-report assessment of depression; $Q_{\text {between }}=1.52, p=.218$, for categorical versus dimensional assessment of stress; $Q_{\text {between }}=0.73, p=.392$, for interview-based versus self-report assessment of stress; $Q_{\text {between }}=$ $1.00, p=.316$, for early- versus late-life stress; see Text A.1 in Appendices). Heterogeneity varied widely in all of these analyses $\left(14.7 \%<I^{2}<87.1 \%\right)$ but was mainly driven by specific studies with high ORs. After excluding just one outlier per moderator subgroup during sensitivity analyses, $I^{2}$ decreased to $0 \% \leq I^{2}<23.9 \%$, with non-significant low heterogeneity in all subgroups. The one exception was the subgroup of studies using an interview to assess stress, which continued to show significant moderate to high and high heterogeneity $60.8 \%<I^{2}<89.0 \%$ during sensitivity analysis (See Text A.1 in Appendices for details).

\section{Meta-regression}

The combined set of predictors explained $R^{2}=41.88 \%$ of heterogeneity with an $I^{2}$ residual heterogeneity of $15.78 \%$, which was non-significant $\left(Q_{E}=56.99, \mathrm{df}=48, p=.175, \mathrm{n}=41\right.$ studies with non-missing information for predictors, yielding 57 effect sizes, see Table 1). Two significant main effects emerged: categorical versus dimensional assessment of stress and interview versus self- 
report assessment of depression, suggesting that studies adopting a categorical assessment of stress and interview assessment of depression were associated with higher effect sizes. Moreover, there was an interaction effect between categorical versus dimensional assessment of stress and interview versus self-report assessment of stress, with significantly higher ORs in studies using interviews to assess stress being observed only in studies that also adopted a categorical assessment of stress. The ORs in studies using a self-report questionnaire to assess stress, regardless of whether these studies adopted a categorical or dimensional approach, were similar. At the same time, it must be noted that the group of studies using both a categorical and interview approach to the assessment of stress, included only 3 effect sizes derived from two studies (Brown et al., 2013; Harkness et al., 2015). _ENREF_49 If we dropped non-significant predictors (categorical/dimensional depression and early-/late-life stress) in the meta-regression, additional studies could be included that were initially excluded in the metaregression because they contained missing values for some of the predictors $(n=47$ studies with in total 65 effect sizes, Table A.3 in Appendices). Results of these analyses were similar for the interaction effect, with higher ORs in studies using categorical and interview assessment of stress, reported in 4 studies yielding 5 effect sizes (Figure 3; Brown et al., 2013; Grabe et al., 2012b; Harkness et al., 2015; Mehta et al., 2012) ${ }^{2}$. In this step, the main effect observed for the studies adopting an interview versus self-report assessment of depression became non-significant. The remaining significant predictors (interview/self-report stress, categorical/dimensional stress, and their interaction) continued to predict a large amount of heterogeneity (explained $R^{2}=13.97 \%$ ), although the residual heterogeneity remained significant in this case $\left(I^{2}=46.03 \%, Q_{E}=113.02, \mathrm{df}=61, p<\right.$ $.0001, \mathrm{n}=48$ studies with in total 66 effect sizes). However, the interaction effect between assessment type of stress (categorical versus continuous) and assessment method of stress (interview-based versus questionnaire-based) was reduced to $b=0.18, S E=0.14, p=.200(95 \% \mathrm{CI}$ of $b=[-0.10 ; 0.46])$ if both Brown et al. (2013) and Mehta et al. (2012) (the two studies with the highest effect sizes) were excluded. It should be noted that the estimation of this (non-significant) interaction effect was then

\footnotetext{
${ }^{2}$ The interaction effect also remained when only one total effect size from the study of Brown et al. (2013) was used.
} 
based on only 2 remaining studies in the group of studies adopting both a categorical and interview assessment of stress (i.e., Grabe et al., 2012b; Harkness et al., 2015).

\section{DISCUSSION}

This study provides an updated meta-analysis of the interaction between 5-HTTLPR and stress in the prediction of depression. It also investigated whether different methodological approaches towards the assessment of stress and depression influenced GxE effects. Results showed that the overall effect size across all included studies ( $\mathrm{n}=51$, totaling $\mathrm{n}=51,449$ participants) was significant $(\mathrm{OR}[95 \% \mathrm{CI}]$ $=1.18[1.09 ; 1.28])$. The current findings therefore support a role of 5-HTTLPR in predicting depression in interaction with stress, even despite the fact that the risk for depression is likely to be influenced by multiple different (polymorphisms of) genes in multiple neuronal pathways (Peyrot et al., 2014). Yet, the obtained aggregated effect size was small.

These results parallel findings reported in a previous meta-analysis by Munafo and colleagues (Munafo et al., 2009) in a much smaller $(\mathrm{n}=9)$ sample of studies $(\mathrm{OR}=1.16,95 \% \mathrm{CI}=[0.89 ; 1.49])$, and by Risch and colleagues (Risch et al., 2009) in a meta-analysis of 14 studies ( $\mathrm{OR}=1.01,95 \% \mathrm{CI}=$ $[0.94 ; 1.10])$. Yet, in both these latter meta-analyses, the obtained effect sizes were not significant. These differences could be due to the larger number of studies included in the present meta-analysis, which may have yielded a more reliable estimate of effects. Importantly, there was no evidence for publication bias, which addresses an often-heard criticism of research in this area (Kaufman et al., 2010).

Overall, there was very little evidence that the way depression and stress were assessed, or the timing of stress, influenced findings concerning interactions between 5HTTLPR and stress in the prediction of depression. Sensitivity analyses showed that heterogeneity between effect sizes of different studies in the overall meta-analysis and in the stratified meta-analyses, mostly resulted from individual studies. There was some evidence that studies using a categorical and interview approach to the assessment of stress yielded larger effect sizes. These findings are in line with suggestions that 
interview-based approaches (Uher and McGuffin, 2008, 2010), which typically adopt a threshold model of stress (Monroe and Simons, 1991), are the most valid approach to assessing the effects of stress. However, this effect was driven by a small number of effect sizes and included effect sizes that were previously identified as outliers (Brown et al., 2013; Mehta et al., 2012). Future research is clearly needed in this area.

\section{Limitations}

Although the present study presents the largest meta-analysis of effect sizes of the interaction between stress and 5-HTTLPR in depression, results should be interpreted in the context of a number of limitations. First, we could not control for gender, ethnicity, and twin status or include the biallelic 5-HTTLPR in all studies (see Table A.1 in Appendices). Yet, in a post-hoc meta-regression, these covariates did not have an impact on GxE effect sizes in a combined analysis with all predictors (results not shown). Furthermore, we did not investigate possible other factors that may explain inconsistencies between GxE results (i.e., there was $46 \%$ unexplained heterogeneity), such as the influence of personality traits (Uher and McGuffin, 2008).

Second, although the 95\%CI of the overall GxE effect was comparatively small, the majority of the individual studies showed a large $95 \% \mathrm{CI}$ that included $\mathrm{OR}=1$. This particular finding raises the question of the quality of GxE studies in relation to other methodological factors that have not been investigated in the current study. For example, there are other classifications of the 5-HTTLPR polymorphism alleles possible (i.e., LL vs. SL vs. SS), including functional classifications (Scheid et al., 2011), which could result in different effect sizes compared to the effect sizes of the allelic classification adopted in the current meta-analysis (i.e., LL vs. SS+SL).

Third, the ratio of included studies to eligible studies was about $48 \%$, with 19 authors who declined the invitation to provide data or perform additional analyses, and 28 authors not responding to requests for additional data or analyses. This raises the question whether including this missing data could lead to different conclusions. This also suggests problems with reporting standards in GxE 
research for conducting meta-analyses. These concerns are somewhat mitigated by the absence of publication bias in the current meta-analysis. Yet, future studies should clearly report all relevant data for future meta-analyses.

\section{Conclusion}

The current meta-analysis found a small, but significant, effect of 5-HTTLPR in interaction with stress in the prediction of depression. There was no evidence of publication bias. Heterogeneity of effect sizes was mostly a result of outliers and not due to how stress and depression were assessed, nor to the timing of stress. There was some evidence, however, that studies adopting an interview and categorical approach to the assessment of stress reported higher effect sizes, although this effect was driven by a small number of studies. The current meta-analysis contributes to ongoing efforts to investigate apparently divergent findings in GxE studies of 5-HTTLPR, stress, and depression (Taylor and Munafò, 2016). Future studies are needed to further disentangle the mechanisms involved in the association between stress, 5-HTTLPR, and depression. Furthermore, given the small effect size, other candidate genes (Aguilera et al., 2009), polygenic scores (Peyrot et al., 2014), and other novel approaches are needed, and might provide more promising ways to assess GxE effects in depression. 


\section{References}

Aguilera, M., Arias, B., Wichers, M., Barrantes-Vidal, N., Moya, J., Villa, H., van Os, J., Ibáñez, M.I., Ruipérez, M.A., Ortet, G., Fañanás, L., 2009. Early adversity and 5-HTT/BDNF genes: New evidence of gene-environment interactions on depressive symptoms in a general population. Psychol Med 39, 1425-1432.

Ambrosini, P.J., Bennett, D.S., Cleland, C.M., Haslam, N., 2002. Taxonicity of adolescent melancholia: A categorical or dimensional construct? J Psychiatr Res 36, 247-256.

Ancelin, M.L., Scali, J., Norton, J., Ritchie, K., Dupuy, A.M., Chaudieu, I., Ryan, J., 2016. Heterogeneity in HPA axis dysregulation and serotonergic vulnerability to depression. Psychoneuroendocrinology 77, 90-94.

Anda, R.F., Felitti, V.J., Bremner, J.D., Walker, J.D., Whitfield, C., Perry, B.D., Dube, S.R., Giles, W.H., 2006. The enduring effects of abuse and related adverse experiences in childhood: A convergence of evidence from neurobiology and epidemiology. Eur Arch Psychiatry Clin Neurosci 256, 174-186.

Antypa, N., Van der Does, A.J.W., 2010. Serotonin transporter gene, childhood emotional abuse and cognitive vulnerability to depression. Genes, Brain and Behavior 9, 615-620.

Appleyard, K., Egeland, B., Dulmen, M.H.M., Sroufe, L.A., 2005. When more is not better: The role of cumulative risk in child behavior outcomes. J Child Psychol Psychiatry 46, 235-245.

Arpawong, T.E., Lee, J., Phillips, D.F., Crimmins, E.M., Levine, M.E., Prescott, C.A., 2016. Effects of recent stress and variation in the serotonin transporter polymorphism (5-HTTLPR) on depressive symptoms: A repeated-measures study of adults age 50 and older. Behavior Genetics 46, 72-88.

Beaver, K.M., Vaughn, M.G., Wright, J.P., DeLisi, M., 2012. An interaction between perceived stress and 5HTTLPR genotype in the prediction of stable depressive symptomatology. Am J Orthopsychiatry 82, 260-266.

Bogdan, R., Agrawal, A., Gaffrey, M.S., Tillman, R., Luby, J.L., 2014. Serotonin transporter-linked polymorphic region (5-HTTLPR) genotype and stressful life events interact to predict 
preschool-onset depression: A replication and developmental extension. J Child Psychol Psychiatry 55, 448-457.

Brown, G.W., Ban, M., Craig, T.K.J., Harris, T.O., Herbert, J., Uher, R., 2013. Serotonin transporter length polymorphism, childhood maltreatment, and chronic depression: A specific geneenvironment interaction. Depress Anxiety 30, 5-13.

Buchmann, A.F., Hellweg, R., Rietschel, M., Treutlein, J., Witt, S.H., Zimmermann, U.S., Schmidt, M.H., Esser, G., Banaschewski, T., Laucht, M., Deuschle, M., 2013. BDNF Val 66 Met and 5-HTTLPR genotype moderate the impact of early psychosocial adversity on plasma brainderived neurotrophic factor and depressive symptoms: A prospective study. Eur Neuropsychopharmacol 23, 902-909.

Carli, V., Mandelli, L., Zaninotto, L., Roy, A., Recchia, L., Stoppia, L., Gatta, V., Sarchiapone, M., Serretti, A., 2011. A protective genetic variant for adverse environments? The role of childhood traumas and serotonin transporter gene on resilience and depressive severity in a high-risk population. Eur Psychiatry 26, 471-478.

Caspi, A., Sugden, K., Moffitt, T.E., Taylor, A., Craig, I.W., Harrington, H., 2003. Influence of life stress on depression: Moderation by a polymorphism in the 5-HTT gene. Science 301, 386389.

Charney, D.S., Manji, H.K., 2004. Life stress, genes, and depression: Multiple pathways lead to increased risk and new opportunities for intervention. Science's STKE 2004, re5.

Chorbov, V.M., Lobos, E.A., Todorov, A.A., Heath, A.C., Botteron, K.N., Todd, R.D., 2007.

Relationship of 5-HTTLPR genotypes and depression risk in the presence of trauma in a female twin sample. Am J Med Genet B Neuropsychiatr Genet 144B, 830-833.

Cochran, W.G., 1950. The comparison of percentages in matched samples. Biometrika 37, 256-266.

Cochran, W.G., 1954. The combination of estimates from different experiments. Biometrics 10, 101 129.

Cohen, J., 1988. Statistical power analysis for the behavioral sciences, 2 ed. Lawrence Erlbaum Associates, Mahwah, NJ. 
Comasco, E., Åslund, C., Oreland, L., Nilsson, K.W., 2013. Three-way interaction effect of 5HTTLPR, BDNF Val66Met, and childhood adversity on depression: A replication study. Eur Neuropsychopharmacol 23, 1300-1306.

Comasco, E., Sylvén, S.M., Papadopoulos, F.C., Oreland, L., Sundström-Poromaa, I., Skalkidou, A., 2011. Postpartum depressive symptoms and the BDNF Val66Met functional polymorphism: Effect of season of delivery. Arch Womens Ment Health 14, 453-463.

Cooper, H., Hedges, L.V., Valentine, J.C., 2009. The handbook of research synthesis and metaanalysis, 2 ed. Russel Sage Foundation, New York, NY.

Coventry, W.L., James, M.R., Eaves, L.J., Gordon, S.D., Gillespie, N.A., Ryan, L., Heath, A.C., Montgomery, G.W., Martin, N.G., Wray, N.R., 2010. Do 5HTTLPR and stress interact in risk for depression and suicidality? Item response analyses of a large sample. Am J Med Genet B Neuropsychiatr Genet 153B, 757-765.

Cruz-Fuentes, C.S., Benjet, C., Martínez-Levy, G.A., Pérez-Molina, A., Briones-Velasco, M., SuárezGonzález, J., 2014. BDNF Met66 modulates the cumulative effect of psychosocial childhood adversities on major depression in adolescents. Brain Behav 4, 290-297.

Dalton, E.D., Hammen, C.L., Najman, J.M., Brennan, P.A., 2014. Genetic susceptibility to family environment: BDNF Val66met and 5-HTTLPR influence depressive symptoms. J Fam Psychol 28, 947-956.

Del Re, A.C., 2013. compute.es: Compute effect sizes. R package version 0.2-2.

DerSimonian, R., Laird, N., 1986. Meta-analysis in clinical trials. Control Clin Trials 7, 177-188.

Duggal, S., Malkoff-Schwartz, S., Birmaher, B., Anderson, B.P., Matty, M.K., Houck, P.R., BaileyOrr, M., Williamson, D.E., Frank, E., 2000. Assessment of life stress in adolescents: Selfreport versus interview methods. J Am Acad Child Adolesc Psychiatry 39, 445-452.

Eaton, W.W., Neufeld, K., Chen, L., Cai, G., 2000. A comparison of self-report and clinical diagnostic interviews for depression: Diagnostic interview schedule and schedules for clinical assessment in neuropsychiatry in the baltimore epidemiologic catchment area follow-up. Arch Gen Psychiatry 57, 217-222. 
Eley, T.C., Sugden, K., Corsico, A., Gregory, A.M., Sham, P., McGuffin, P., Plomin, R., Craig, I.W., 2004. Gene-environment interaction analysis of serotonin system markers with adolescent depression. Mol Psychiatry 9, 908-915.

Enns, M.W., Larsen, D.K., Cox, B.J., 2000. Discrepancies between self and observer ratings of depression: The relationship to demographic, clinical and personality variables. J Affect Disord 60, 33-41.

Fandiño-Losada, A., Wei, Y., Åberg, E., Sjöholm, L.K., Lavebratt, C., Forsell, Y., 2013. Influence of serotonin transporter promoter variation on the effects of separation from parent/partner on depression. J Affect Disord 144, 216-224.

Fergusson, D.M., Horwood, L.J., Miller, A.L., Kennedy, M.A., 2011. Life stress, 5-HTTLPR and mental disorder: Findings from a 30-year longitudinal study. Br J Psychiatry 198, 129-135.

Ford, B.Q., Mauss, I.B., Troy, A.S., Smolen, A., Hankin, B., 2014. Emotion regulation moderates the risk associated with the 5-HTT gene and stress in children. Emotion 14, 930-939.

Fraley, R.C., Spieker, S.J., 2003. Are infant attachment patterns continuously or categorically distributed? A taxometric analysis of strange situation behavior. Dev Psychol 39, 387-404.

Gibb, B.E., Uhrlass, D.J., Grassia, M., Benas, J.S., McGeary, J., 2009. Children's inferential styles, 5HTTLPR genotype, and maternal expressed emotion-criticism: An integrated model for the intergenerational transmission of depression. J Abnorm Psychol 118, 734-745.

Grabe, H.J., Schwahn, C., Mahler, J., Appel, K., Schulz, A., Spitzer, C., Fenske, K., Barnow, S., Freyberger, H.J., Teumer, A., Petersmann, A., Biffar, R., Rosskopf, D., John, U., Völzke, H., 2012a. Genetic epistasis between the brain-derived neurotrophic factor Val66Met polymorphism and the 5-HTT promoter polymorphism moderates the susceptibility to depressive disorders after childhood abuse. Prog Neuropsychopharmacol Biol Psychiatry 36, 264-270.

Grabe, H.J., Schwahn, C., Mahler, J., Schulz, A., Spitzer, C., Fenske, K., Appel, K., Barnow, S., Nauck, M., Schomerus, G., Biffar, R., Rosskopf, D., John, U., Völzke, H., Freyberger, H.J., 2012b. Moderation of adult depression by the serotonin transporter promoter variant (5- 
HTTLPR), childhood abuse and adult traumatic events in a general population sample. Am J Med Genet B Neuropsychiatr Genet 159B, 298-309.

Gutierrez, B., Bellon, J.A., Rivera, M., Molina, E., King, M., Marston, L., Torres-Gonzalez, F., Moreno-Kustner, B., Moreno-Peral, P., Motrico, E., Monton-Franco, C., GildeGomezBarragan, M.J., Sanchez-Celaya, M., Diaz-Barreiros, M.A., Vicens, C., de Dios Luna, J., Nazareth, I., Cervilla, J., 2015. The risk for major depression conferred by childhood maltreatment is multiplied by BDNF and SERT genetic vulnerability: A replication study. $\mathrm{J}$ Psychiatry Neurosci 40, 187-196.

Hammen, C., 2005. Stress and Depression. Annu Rev Clin Psychol 1, 293-319.

Hammen, C., Henry, R., Daley, S.E., 2000. Depression and sensitization to stressors among young women as a function of childhood adversity. J Consult Clin Psychol 68, 782-787.

Hankin, B.L., Fraley, R.C., Lahey, B.B., Waldman, I.D., 2005. Is depression best viewed as a continuum or discrete category? A taxometric analysis of childhood and adolescent depression in a population-based sample. J Abnorm Psychol 114, 96-110.

Harkness, K.L., Strauss, J., Bagby, M.R., Stewart, J.G., Larocque, C., Mazurka, R., Ravindran, A., Wynne-Edwards, K.E., Rector, N.A., Kennedy, J., 2015. Interactions between childhood maltreatment and brain-derived neurotrophic factor and serotonin transporter polymorphisms on depression symptoms. Psychiatry Res 229, 609-612.

Haslam, N., Beck, A.T., 1994. Subtyping major depression: A taxometric analysis. J Abnorm Psychol 103, 686-692.

Heim, C., Binder, E.B., 2012. Current research trends in early life stress and depression: Review of human studies on sensitive periods, gene-environment interactions, and epigenetics. Exp Neurol 233, 102-111.

Higgins, J.P., Thompson, S.G., Deeks, J.J., Altman, D.G., 2003. Measuring inconsistency in metaanalyses. BMJ 327, 557-560.

Hunt, M., Auriemma, J., Cashaw, A.C., 2003. Self-report bias and underreporting of depression on the BDI-II. J Pers Assess 80, 26-30. 
Jacobs, N., Kenis, G., Peeters, F., Derom, C., Vlietinck, R., van Os, J., 2006. Stress-related negative affectivity and genetically altered serotonin transporter function: Evidence of synergism in shaping risk of depression. Arch Gen Psychiatry 63, 989-996.

Joiner, T.E., Jr., Walker, R.L., Pettit, J.W., Perez, M., Cukrowicz, K.C., 2005. Evidence-based assessment of depression in adults. Psychol Assess 17, 267-277.

Juhasz, G., Gonda, X., Hullam, G., Eszlari, N., Kovacs, D., Lazary, J., Pap, D., Petschner, P., Elliott, R., Deakin, J.F.W., Anderson, I.M., Antal, P., Lesch, K.-P., Bagdy, G., 2015. Variability in the effect of 5-HTTLPR on depression in a large European population: the role of age, symptom profile, type and intensity of life stressors. PloS one 10, e0116316.

Karg, K., Burmeister, M., Shedden, K., Sen, S., 2011. The serotonin transporter promoter variant (5HTTLPR), stress, and depression meta-analysis revisited: Evidence of genetic moderation. Arch Gen Psychiatry 68, 444-454.

Kaufman, J., Gelernter, J., Kaffman, A., Caspi, A., Moffitt, T., 2010. Arguable assumptions, debatable conclusions. Biol Psychiatry 67, e19-20; author reply e21-13.

Kendler, K.S., Karkowski, L.M., Prescott, C.A., 1999. Causal relationship between stressful life events and the onset of major depression. Am J Psychiatry 156, 837-841.

Kessler, R.C., 1997. The effects of stressful life events on depression. Annu Rev Psychol 48, 191-214.

Kim, J.-M., Stewart, R., Kim, S.-W., Yang, S.-J., Shin, I.-S., Kim, Y.-H., Yoon, J.-S., 2007. Interactions between life stressors and susceptibility genes (5-HTTLPR and BDNF) on depression in Korean elders. Biol Psychiatry 62, 423-428.

Kudinova, A.Y., McGeary, J.E., Knopik, V.S., Gibb, B.E., 2015. Brain derived neurotrophic factor (BDNF) polymorphism moderates the interactive effect of 5-HTTLPR polymorphism and childhood abuse on diagnoses of major depression in women. Psychiatry Res 225, 746-747.

Kurrikoff, T., Hiio, K., Täht, K., Harro, J., Veidebaum, T., 2013. The 5-HTTLPR genotype and depressiveness link: Contribution of aspects of environment and gender. Psychiatry Res 209, $126-127$ 
La Greca, A.M., Lai, B.S., Joormann, J., Auslander, B.B., Short, M.A., 2013. Children's risk and resilience following a natural disaster: Genetic vulnerability, posttraumatic stress, and depression. J Affect Disord 151, 860-867.

Lacey, C.J., Salzberg, M.R., D'Souza, W.J., 2014. Serotonin transporter gene x environment and risk of depression in community-treated epilepsy. Epilepsy Behav 39, 33-37.

Laucht, M., Treutlein, J., Blomeyer, D., Buchmann, A.F., Schmid, B., Becker, K., 2009. Interaction between the 5-HTTLPR serotonin transporter polymorphism and environmental adversity for mood and anxiety psychopathology: Evidence from a high-risk community sample of young adults. Int J Neuropsychopharmacol 12, 737-747.

Lavigne, J.V., Herzing, L.B.K., Cook, E.H., Lebailly, S.A., Gouze, K.R., Hopkins, J.C., Bryant, F.B., 2013. Gene $\times$ Environment effects of serotonin transporter, dopamine receptor D4, and monoamine oxidase A genes with contextual and parenting risk factors on symptoms of oppositional defiant disorder, anxiety, and depression in a community sample of 4-year-old children. Dev Psychopathol 25, 555-575.

Lazary, J., Lazary, A., Gonda, X., Benko, A., Molnar, E., Juhasz, G., Bagdy, G., 2008. New evidence for the association of the serotonin transporter gene (SLC6A4) haplotypes, threatening life events, and depressive phenotype. Biol Psychiatry 64, 498-504.

Lei, M.-K., Beach, S.R.H., Simons, R.L., Philibert, R.A., 2015. Neighborhood crime and depressive symptoms among African American women: Genetic moderation and epigenetic mediation of effects. Soc Sci Med 146, 120-128.

Lesch, K.P., 2004. Gene-environment interaction and the genetics of depression. J Psychiatry Neurosci 29, 174-184.

Lewinsohn, P.M., Rohde, P., Gau, J.M., 2003. Comparability of self-report checklist and interview data in the assessment of stressful life events in young adults. Psychol Rep 93, 459-471.

Lipsey, M.W., Wilson, D.B., 2001. Practical meta-analysis. Sage Publications, Inc., London, UK.

Logan, D.E., Claar, R.L., Scharff, L., 2008. Social desirability response bias and self-report of psychological distress in pediatric chronic pain patients. Pain 136, 366-372. 
Lohoff, F.W., 2010. Overview of the genetics of major depressive disorder. Curr Psychiatry Rep. 12, $539-546$

Lupien, S.J., McEwen, B.S., Gunnar, M.R., Heim, C., 2009. Effects of stress throughout the lifespan on the brain, behaviour and cognition. Nat Rev Neurosci 10, 434-445.

McLaughlin, K.A., Conron, K.J., Koenen, K.C., Gilman, S.E., 2010. Childhood adversity, adult stressful life events, and risk of past-year psychiatric disorder: A test of the stress sensitization hypothesis in a population-based sample of adults. Psychol Med 40, 1647-1658.

Mehta, D., Quast, C., Fasching, P.A., Seifert, A., Voigt, F., Beckmann, M.W., Faschingbauer, F., Burger, P., Ekici, A.B., Kornhuber, J., Binder, E.B., Goecke, T.W., 2012. The 5-HTTLPR polymorphism modulates the influence on environmental stressors on peripartum depression symptoms. J Affect Disord 136, 1192-1197.

Ming, Q.-S., Zhang, Y., Chai, Q.-1., Chen, H.-Y., Hou, C.-J., Wang, M.-C., Wang, Y.-P., Cai, L., Zhu, X.-Z., Yi, J.-Y., Yao, S.-Q., 2013. Interaction between a serotonin transporter gene promoter region polymorphism and stress predicts depressive symptoms in Chinese adolescents: A multi-wave longitudinal study. BMC Psychiatry 13, 1-7.

Mitchell, K.J., Tynes, B., Umaña-Taylor, A.J., Williams, D., 2015. Cumulative experiences with life adversity: Identifying critical levels for targeting prevention efforts. J Adolesc 43, 63-71.

Monroe, S.M., Simons, A.D., 1991. Diathesis-stress theories in the context of life stress research: Implications for the depressive disorders. Psychopharmacol Bull 110, 406-425.

Munafo, M.R., Durrant, C., Lewis, G., Flint, J., 2009. Gene x environment interactions at the serotonin transporter locus. Biol Psychiatry 65, 211-219.

Nederhof, E., Bouma, E.M.C., Oldehinkel, A.J., Ormel, J., 2010. Interaction between childhood adversity, brain-derived neurotrophic factor val/met and serotonin transporter promoter polymorphism on depression: The TRAILS study. Biol Psychiatry 68, 209-212.

Nestler, E.J., Barrot, M., DiLeone, R.J., Eisch, A.J., Gold, S.J., Monteggia, L.M., 2002. Neurobiology of depression. Neuron 34, 13-25. 
Peyrot, W.J., Milaneschi, Y., Abdellaoui, A., Sullivan, P.F., Hottenga, J.J., Boomsma, D.I., Penninx, B.W., 2014. Effect of polygenic risk scores on depression in childhood trauma. Br J Psychiatry 205, 113-119.

Priess-Groben, H.A., Hyde, J.S., 2013. 5-HTTLPR X stress in adolescent depression: Moderation by MAOA and gender. J Abnorm Child Psychol 41, 281-294.

R Development Core Team, 2014. R: A language and environment for statistical computing. R Foundation for Statistical Computing, Vienna, Austria.

Ressler, K.J., Bradley, B., Mercer, K.B., Deveau, T.C., Smith, A.K., Gillespie, C.F., Nemeroff, C.B., Cubells, J.F., Binder, E.B., 2010. Polymorphisms in CRHR1 and the serotonin transporter loci: Gene $\mathrm{x}$ gene $\mathrm{x}$ environment interactions on depressive symptoms. Am J Med Genet B Neuropsychiatr Genet 153B, 812-824.

Risch, N., Herrell, R., Lehner, T., Liang, K.Y., Eaves, L., Hoh, J., Griem, A., Kovacs, M., Ott, J., Merikangas, K.R., 2009. Interaction between the serotonin transporter gene (5-HTTLPR), stressful life events, and risk of depression: A meta-analysis. JAMA 301, 2462-2471.

Rocha, T.B., Hutz, M.H., Salatino-Oliveira, A., Genro, J.P., Polanczyk, G.V., Sato, J.R., Wehrmeister, F.C., Barros, F.C., Menezes, A.M., Rohde, L.A., Anselmi, L., Kieling, C., 2015. Geneenvironment interaction in youth depression: Replication of the 5-HTTLPR moderation in a diverse setting. Am J Psychiatry 172, 978-985.

Ruscio, J., Ruscio, A.M., 2000. Informing the continuity controversy: A taxometric analysis of depression. J Abnorm Psychol 109, 473-487.

Scheid, J.M., Holzman, C.B., Jones, N., Friderici, K.H., Jernigan, K.A., Symonds, L.L., Sikorskii, A., Fisher, R., 2011. Life stressors and 5-HTTLPR interaction in relation to midpregnancy depressive symptoms among African-American women. Psychiat Genet 21, 271-280.

Scheid, J.M., Holzman, C.B., Jones, N., Friderici, K.H., Nummy, K.A., Symonds, L.L., Sikorskii, A., Regier, M.K., Fisher, R., 2007. Depressive symptoms in mid-pregnancy, lifetime stressors and the 5-HTTLPR genotype. Genes Brain Behav 6, 453-464.

Schwarzer, G., 2016. meta: General package for meta-analysis. R package version 4.5-0. 
Sjöberg, R.L., Nilsson, K.W., Nordquist, N., Ohrvik, J., Leppert, J., Lindstrom, L., Oreland, L., 2006. Development of depression: Sex and the interaction between environment and a promoter polymorphism of the serotonin transporter gene. Int J Neuropsychopharmacol 9, 443-449.

Slade, T., Andrews, G., 2005. Latent structure of depression in a community sample: A taxometric analysis. Psychol Med 35, 489-497.

Stuart, A.L., Pasco, J.A., Jacka, F.N., Brennan, S.L., Berk, M., Williams, L.J., 2014. Comparison of self-report and structured clinical interview in the identification of depression. Compr Psychiatry 55, 866-869.

Surtees, P.G., Wainwright, N.W., Willis-Owen, S.A., Luben, R., Day, N.E., Flint, J., 2006. Social adversity, the serotonin transporter (5-HTTLPR) polymorphism and major depressive disorder. Biol Psychiatry 59, 224-229.

Taylor, A.E., Munafò, M.R., 2016. Triangulating meta-analyses: The example of the serotonin transporter gene, stressful life events and major depression. BMC Psychology 4, 23.

Taylor, S.E., Way, B.M., Welch, W.T., Hilmert, C.J., Lehman, B.J., Eisenberger, N.I., 2006. Early family environment, current adversity, the serotonin transporter promoter polymorphism, and depressive symptomatology. Biol Psychiatry 60, 671-676.

Tennant, C., 2002. Life events, stress and depression: A review of recent findings. Aust N Z J Psychol $36,173-182$.

Tsuboi, H., Sakakibara, H., Yamakawa-Kobayashi, K., Tatsumi, A., Inamori, T., Hamamoto, R., Suzuki, A., Shimoi, K., 2011. Val1483Ile polymorphism in the fatty acid synthase gene was associated with depressive symptoms under the influence of psychological stress. J Affect Disord 134, 448-452.

Uher, R., McGuffin, P., 2008. The moderation by the serotonin transporter gene of environmental adversity in the aetiology of mental illness: Review and methodological analysis. Mol Psychiatry 13, 131-146.

Uher, R., McGuffin, P., 2010. The moderation by the serotonin transporter gene of environmental adversity in the etiology of depression: 2009 update. Mol Psychiatry 15, 18-22. 
van Houwelingen, H.C., Arends, L.R., Stijnen, T., 2002. Advanced methods in meta-analysis: Multivariate approach and meta-regression. Stat Med 21, 589-624.

van Roekel, E., Engels, R.C., Verhagen, M., Goossens, L., Scholte, R.H., 2011. Parental depressive feelings, parental support, and the serotonin transporter gene as predictors of adolescent depressive feelings: A latent growth curve analysis. J Youth Adolesc 40, 453-462.

Vinberg, M., Mellerup, E., Andersen, P.K., Bennike, B., Kessing, L.V., 2010. Variations in 5HTTLPR: Relation to familiar risk of affective disorder, life events, neuroticism and cortisol. Prog Neuropsychopharmacol Biol Psychiatry 34, 86-91.

Vrshek-Schallhorn, S., Mineka, S., Zinbarg, R.E., Craske, M.G., Griffith, J.W., Sutton, J., Redei, E.E., Wolitzky-Taylor, K., Hammen, C., Adam, E.K., 2014. Refining the candidate environment: Interpersonal stress, the serotonin transporter polymorphism, and gene-environment interactions in major depression. Clin Psychol Sci 2, 235-248.

Wichers, M., Kenis, G., Jacobs, N., Mengelers, R., Derom, C., Vlietinck, R., van Os, J., 2008. The BDNF Val66Met $\times 5$-HTTLPR $\times$ child adversity interaction and depressive symptoms: An attempt at replication. Am J Med Genet B Neuropsychiatr Genet 147B, 120-123. 
Figure 1

Study

Aguilera et al., 2009

Ancelin et al., 2016

Antypa et al., 2010

Arpawong et al., 2016

Beaver et al., 2012

Bogdan et al., 2014

Brown et al., 2013

Chorbov et al., 2007

Comasco et al., 2011

Comasco et al., 2013

Coventry et al., 2010

Cruz-Fuentes et al., 2014

Dalton et al., 2014

Eley et al., 2004

Fandiño-Losada et al., 2013

Fergusson et al., 2011

Ford et al., 2014

Gibb et al., 2009

Grabe et al., 2012a / Grabe et al., 2012b

Gutiérrez et al., 2014

Harkness et al., 2015

Jacobs et al., 2006 / Wichers et al., 2008

Juhasz et al., 2015

Kim et al., 2007

Kudinova et al., 2015

Kurrikoff et al., 2013

La Greca et al., 2013

Lacey et al., 2014

Lavigne et al., 2013

Lazary et al., 2008

Lei et al., 2015

Mehta et al., 2012

Ming et al., 2013

Nederhof et al., 2010

Pries-Groben et al., 2013

Ressler et al., 2010

Rocha et al., 2015

Scheid et al., 2007

Scheid et al., 2011

Sjöberg et al., 2006

Surtees et al., 2006

Taylor et al., 2006

Tsuboi et al., 2011

Van Roekel et al., 2011

Vinberg et al., 2010

Vrshek-Schallhorn et al., 2014

Fixed effect model

Random effects model

\section{TE seTE}

$0.07 \quad 0.16$

$\begin{array}{ll}-1.22 & 0.73 \\ -0.32 & 0.60\end{array}$

$-0.32 \quad 0.60$

$0.02 \quad 0.08$

$\begin{array}{ll}0.29 & 0.09\end{array}$

$\begin{array}{ll}0.17 & 0.18\end{array}$

$\begin{array}{ll}0.96 & 0.31\end{array}$

$\begin{array}{cc}0.00 & 0.13 \\ -0.48 & 0.62\end{array}$

$\begin{array}{ll}-0.48 & 0.62\end{array}$

$\begin{array}{ll}-0.22 & 0.41\end{array}$

$\begin{array}{ll}0.22 & 0.09\end{array}$

$\begin{array}{ll}-0.01 & 0.07\end{array}$

$\begin{array}{lll}0.04 & 0.42\end{array}$

$\begin{array}{ll}0.30 & 0.20\end{array}$

$\begin{array}{lll}0.67 & 0.60\end{array}$

$0.12 \quad 0.30$

$\begin{array}{ll}0.06 & 0.32\end{array}$

$\begin{array}{lll}0.38 & 0.26\end{array}$

$\begin{array}{ll}0.54 & 0.37\end{array}$

$\begin{array}{lll}0.14 & 0.08\end{array}$

$\begin{array}{ll}0.34 & 0.23\end{array}$

$\begin{array}{ll}0.16 & 0.20\end{array}$

$0.12 \quad 0.20$

$\begin{array}{lll}0.07 & 0.06\end{array}$

$\begin{array}{ll}0.22 & 0.09\end{array}$

0.690 .58

$0.12 \quad 0.16$

$\begin{array}{ll}0.20 & 0.34\end{array}$

$\begin{array}{lll}0.05 & 0.17\end{array}$

$\begin{array}{lll}0.37 & 0.28\end{array}$

$0.32 \quad 0.15$

$\begin{array}{ll}0.25 & 0.37\end{array}$

$\begin{array}{ll}1.38 & 0.20\end{array}$

$\begin{array}{ll}0.09 & 0.24\end{array}$

$0.03 \quad 0.10$

$\begin{array}{lll}-0.20 & 0.28\end{array}$

$\begin{array}{lll}0.89 & 0.58\end{array}$

$\begin{array}{ll}0.63 & 0.29\end{array}$

$\begin{array}{cc}-0.38 & 0.60\end{array}$

$\begin{array}{lll}0.15 & 0.32\end{array}$

$\begin{array}{ll}0.25 & 0.28\end{array}$

$\begin{array}{rr}-0.09 & 0.13\end{array}$

$\begin{array}{ll}0.08 & 0.35\end{array}$

$\begin{array}{ll}-0.36 & 0.28\end{array}$

$\begin{array}{ll}0.14 & 0.21\end{array}$

$\begin{array}{lll}0.58 & 0.26\end{array}$

$\begin{array}{lll}0.28 & 0.18\end{array}$

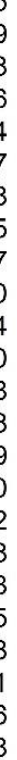
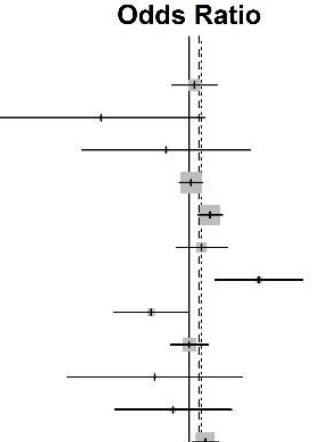

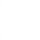

(

(1)

8

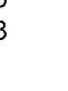

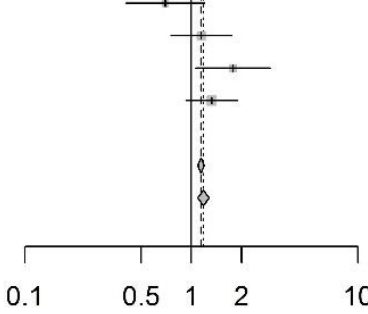

OR $\quad 95 \%$-Cl W(fixed) W(random)

$1.07[0.79 ; 1.46] \quad 2.1 \% \quad 2.9 \%$

$0.30[0.07 ; 1.23] \quad 0.1 \% \quad 0.3 \%$

$0.72[0.23 ; 2.33] \quad 0.1 \% \quad 0.4 \%$

$1.02[0.87 ; 1.20] \quad 7.5 \% \quad 4.5 \%$

$1.33[1.12 ; 1.58] \quad 6.6 \% \quad 4.4 \%$

$1.19[0.83 ; 1.69] \quad 1.6 \% \quad 2.6 \%$

$2.62[1.43 ; 4.83] \quad 0.5 \% \quad 1.3 \%$

$0.59[0.35 ; 0.99] \quad 0.7 \% \quad 1.6 \%$

$1.00[0.77 ; 1.30] \quad 2.9 \% \quad 3.4 \%$

$0.62[0.18 ; 2.08] \quad 0.1 \% \quad 0.4 \%$

$0.80[0.36 ; 1.79] \quad 0.3 \% \quad 0.8 \%$

$1.25[1.04 ; 1.50] \quad 5.9 \% \quad 4.3 \%$

$0.99[0.86 ; 1.13] \quad 11.1 \% \quad 4.8 \%$

$1.04[0.46 ; 2.38] \quad 0.3 \% \quad 0.8 \%$

$1.35[0.92 ; 1.98] \quad 1.3 \% \quad 2.4 \%$

$1.95[0.60 ; 6.30] \quad 0.1 \% \quad 0.4 \%$

$1.13[0.63 ; 2.05] \quad 0.6 \% \quad 1.3 \%$

$1.06[0.57 ; 1.98] \quad 0.5 \% \quad 1.2 \%$

$1.47[0.89 ; 2.43] \quad 0.8 \% \quad 1.7 \%$

$1.72[0.82 ; 3.57] \quad 0.4 \% \quad 0.9 \%$

$1.14[0.98 ; 1.34] \quad 7.8 \% \quad 4.5 \%$

$1.40[0.88 ; 2.21] \quad 0.9 \% \quad 1.9 \%$

$1.17[0.80 ; 1.73] \quad 1.3 \% \quad 2.3 \%$

$1.13[0.75 ; 1.68] \quad 1.2 \% \quad 2.2 \%$

$1.08[0.95 ; 1.22] \quad 12.9 \% \quad 4.9 \%$

$1.24[1.05 ; 1.48] \quad 6.6 \% \quad 4.4 \%$

$2.00[0.65 ; 6.20] \quad 0.2 \% \quad 0.4 \%$

$1.12[0.82 ; 1.53] \quad 2.1 \% \quad 3.0 \%$

$1.22[0.62 ; 2.39]-0.4 \% \quad 1.1 \%$

$1.05[0.75 ; 1.46] \quad 1.8 \% \quad 2.7 \%$

$1.45[0.83 ; 2.53] \quad 0.6 \% \quad 1.4 \%$

$1.38[1.02 ; 1.86] \quad 2.2 \% \quad 3.0 \%$

$1.29[0.62 ; 2.67] \quad 0.4 \% \quad 0.9 \%$

$3.99[2.71 ; 5.88] \quad 1.3 \% \quad 2.3 \%$

$1.09[0.68 ; 1.76] \quad 0.9 \% \quad 1.8 \%$

$1.03[0.85 ; 1.25] \quad 5.2 \% \quad 4.1 \%$

$0.82[0.47 ; 1.42] \quad 0.6 \% \quad 1.4 \%$

$2.43[0.78 ; 7.60] \quad 0.2 \% \quad 0.4 \%$

$1.89[1.07 ; 3.32] \quad 0.6 \% \quad 1.4 \%$

$0.68[0.21 ; 2.20] \quad 0.1 \% \quad 0.4 \%$

$1.16[0.62 ; 2.17] \quad 0.5 \% \quad 1.2 \%$

$1.28[0.75 ; 2.20] \quad 0.7 \% \quad 1.5 \%$

$0.91[0.71 ; 1.17] \quad 3.2 \% \quad 3.5 \%$

$1.09[0.55 ; 2.15] \quad 0.4 \% \quad 1.1 \%$

$0.70[0.40 ; 1.20] \quad 0.7 \% \quad 1.5 \%$

$1.15[0.75 ; 1.74] \quad 1.1 \% \quad 2.1 \%$

$1.78[1.06 ; 2.98] \quad 0.7 \% \quad 1.6 \%$

$1.33[0.93 ; 1.90] \quad 1.5 \% \quad 2.5 \%$

$1.14[1.09 ; 1.20] \quad 100 \% \quad--$

$1.18[1.09 ; 1.28] \quad--\quad 100 \%$ 
Figure 2

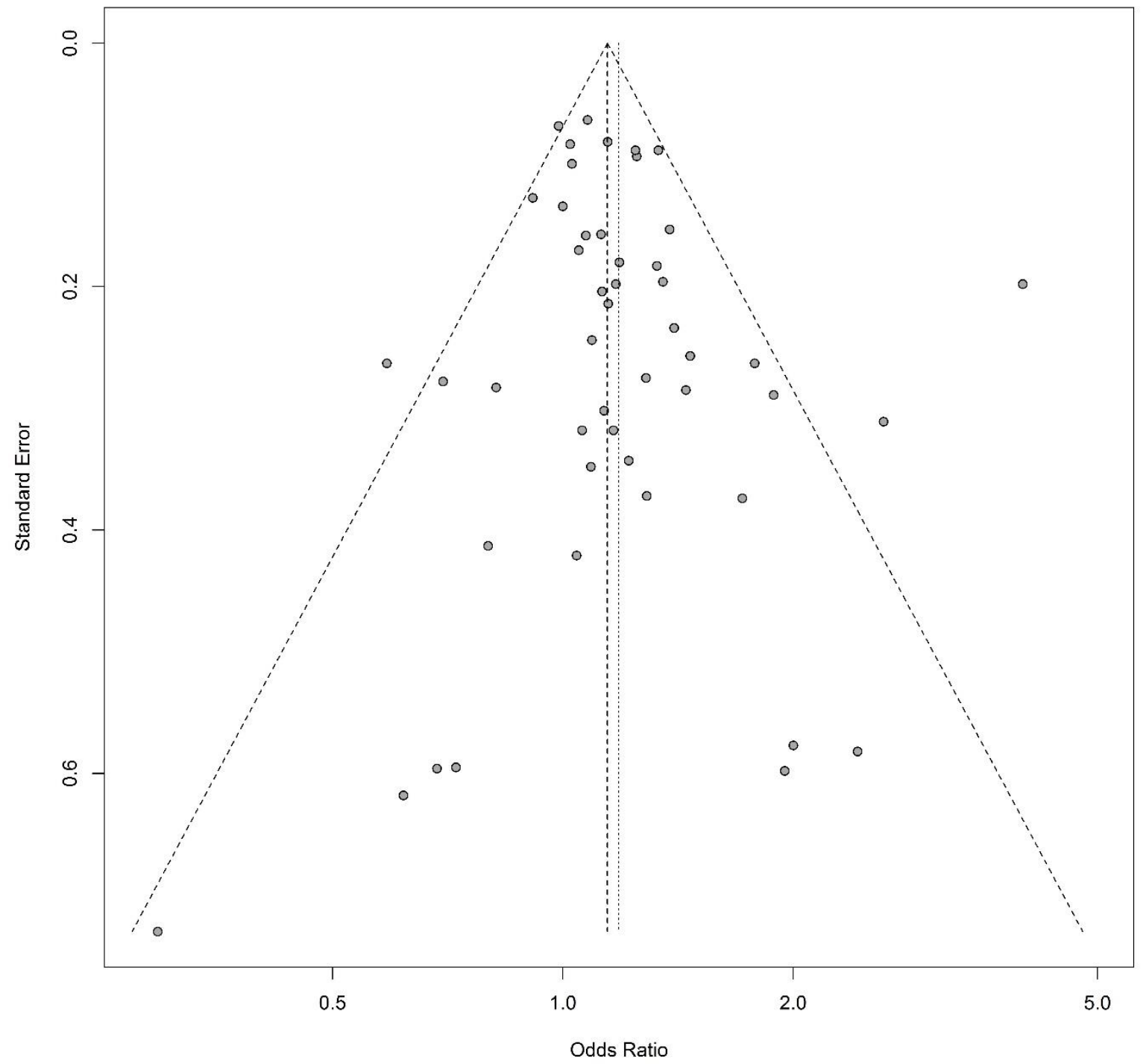


26

Figure 3

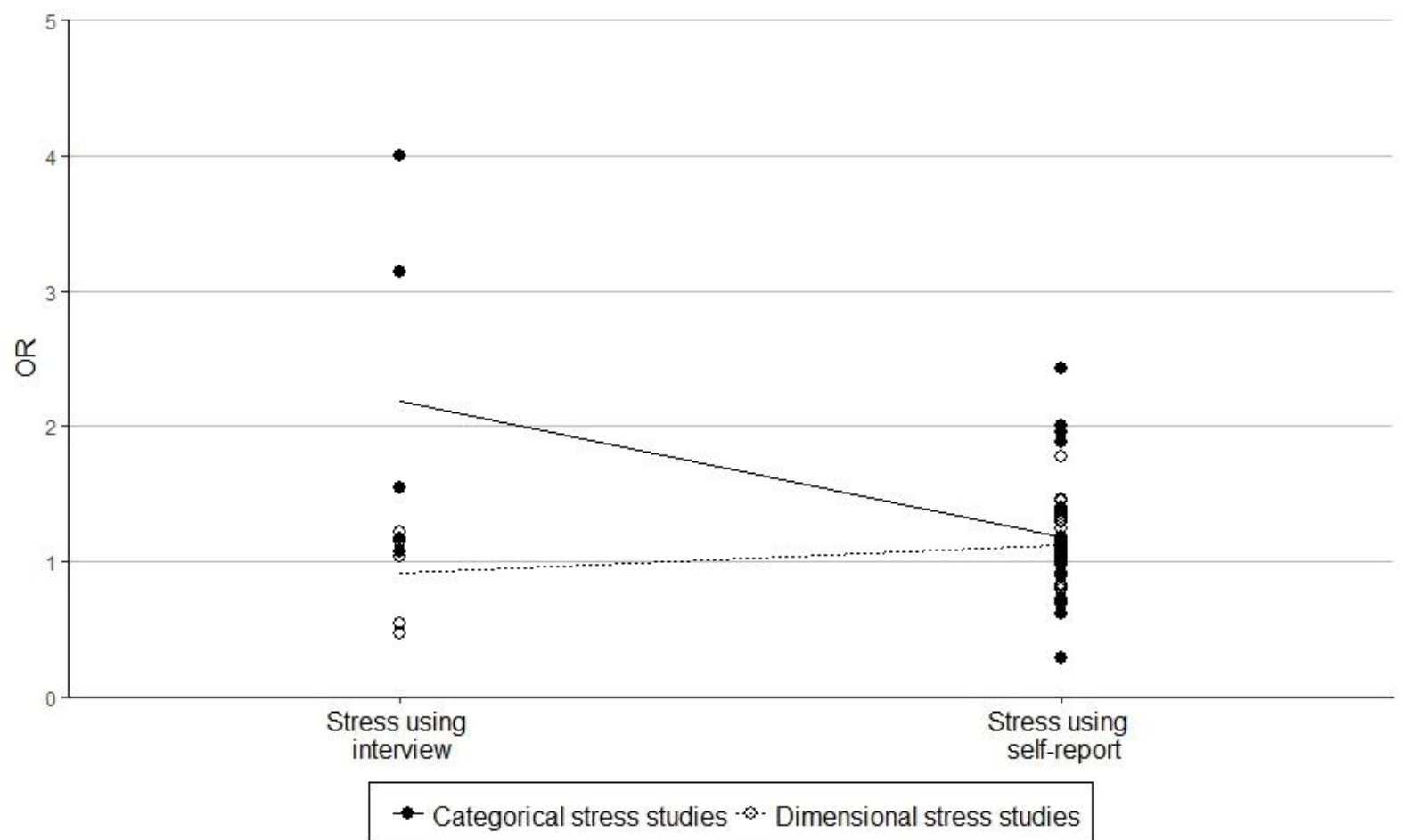


$\underline{\text { Table } 1}$

Table 1

Meta-regression estimates

\begin{tabular}{|c|c|c|c|c|}
\hline Predictor & $b$ & $S E$ & $p$-value & $95 \% \mathrm{CI}$ of $b$ \\
\hline Intercept & 0.49 & 0.16 & .002 & {$[0.18 ; 0.80]$} \\
\hline Sample identification & -0.00 & 0.00 & .515 & {$[-0.01 ; 0.01]$} \\
\hline \multicolumn{5}{|l|}{ Depression measurement } \\
\hline Categorical/Dimensional (a) & -0.02 & 0.09 & .847 & {$[-0.20 ; 0.17]$} \\
\hline Interview/Self-report & -0.16 & 0.07 & .029 & {$[-0.31 ;-0.02]$} \\
\hline (a) $\mathrm{x}(\mathrm{b})$ interaction & 0.10 & 0.11 & .342 & {$[-0.11 ; 0.32]$} \\
\hline
\end{tabular}

Stress measurement

Categorical/Dimensional (c) $\quad-0.50 \quad 0.18 \quad .005 \quad[-0.85 ;-0.15]$

Interview/Self-report $\quad$ (d) $\quad-0.29 \quad 0.16 \quad .071 \quad[-0.61 ; 0.03]$

$\left.\begin{array}{lllll}\text { (c) } x(d) \text { interaction } & 0.49 & 0.19 & .009 & {[0.12 ; 0.85}\end{array}\right]$

Early-life/Late-life stress $\quad-0.01 \quad 0.05 \quad .839 \quad[-0.10 ; 0.08]$

Note: $b$ represents the change in log odds if subgroup changes from e.g. categorical depression measurement to dimensional depression measurement. 